\title{
Enterprise risk grade evaluation based on risk management
}

\author{
Xintong Zhu', a , Qian $\mathrm{Li}^{1, \mathrm{~b}}$ and Yu Wang * 1,c \\ ${ }^{1}$ Sichuan normal university, Chengdu,Sichuan province,China \\ a844033708@qq.com, 호12730097@qq.com, 3 380459781@qq.com
}

\begin{abstract}
Keywords: risk management; enterprise risk; enterprise risk grade evaluation
Abstract: Based on the ideas of risk classification and hierarchical supervision in risk management, the paper divides enterprises into several levels according to enterprise risk and other relevant factors, and establishes an index system of enterprise risk class evaluation through carrying out the work of expert investigation, it introduces The Analytic Hierarchy Process in detail and carrise out qualitative and quantitative analysis of the various elements of the business, combined with the characteristics of the industry to estimate the risk of enterprises, to achieve a classification of enterprise risk assessment, including the assessment and adjustment of risk level, so as to implement the level of safety risk management level, arrived at there are different levels of risk-oriented enterprises to be targeted regulatory measures.
\end{abstract}

\section{Introduction}

In enterprises production, the risk must exist, how to minimize the risk is a major problem that many companies need to face[1]. Different enterprises are faced with different risks, categories may different and probability are various, the degree of attention of enterprises and management methods are different, the most obvious problem is not find the points of the level of corporate safety risk and ignoring the danger of business, which requires a targeted index system to support, so that to appraise the risk of enterprise safety production and to find out supervision methods among the enterprises with different risk factors is important for the enterprises to achieve safety production [2,3]. This study is based on risk management to appraise inherent and dynamic risks in different enterprises, and analyzing the relation of different enterprises exposure to environmental hazards and health and safety, and intuitively reflect the degree of its danger. According to the conclusions to assess the classification levels so that enterprises probably know their own level ofsafety, in accordance with the level of production safety risk management, select different safety regulatory measures, reasonable arrangements for the number of industry regulatory inspection. And the enterprises can carry out risk management more effectively and also reduce different businesses risk and provide basis.

\section{Risk Management}

Risk management is a kind of management activity that identifies and measures risk, uses reasonable economic and technical means to deal with the risk and obtains the maximumsafety with the lowest cost. The overall goal of risk management is to manage the economic cost with minimal risk, obtain the maximum safety guarantee and realize the maximization of the value of the economic unit. The procedures include risk identification, risk measurement, risk management and risk management evaluation. Effectively managing the risks exists in the enterprise is conducive to the stability of the production and operation activities of the enterprise, and help to improve the economic benefits of enterprises and establish a good social image. Risk management is of great significance to enterprises[4,5].

\section{Enterprise Risk Rating Evaluation Index System Established}

In order to clarify the level of risk assessment of enterprises contained in the first and second level elements, launched an expert questionnaire. After expert questionnaire survey results, sorted out the specific indicators to measure the risk of enterprises. The enterprise risk rating evaluation index 
system is divided into three levels, namely the target level, the first level elements and the second level elements.

\section{Factors at All Levels to Determine the Basis for Weight}

Analytic hierarchy process. Analytic Hierarchy Process (AHP) is a decision-making method that decomposes the elements which always related to decision-making into objectives, criteria and programs, and then makes qualitative and quantitative analysis based on it. Its application includes the establishment of hierarchical structure and the comparison of judgment matrix, for a certain standard, the weight of each alternative element is calculated in three aspects. The crux of the problem lies in whether a reasonable judgment matrix can be obtained [6,7]. The method of expert investigation gets the judgment matrix, when the experts tend to agree, then the weight should be a comprehensive consideration of various factors, the weight of science.

Basic steps.(1) Construct judgment matrix, as shown in Table 1.(2) calculate the weight vector. (3) consistency test.

Table 1. The table of determine matrix sample

\begin{tabular}{lllll}
\hline A & B1 & B2 & $\cdots \cdots$ & BM \\
\hline B1 & b11 & B12 & $\cdots \cdots$ & b1m \\
B2 & b21 & b22 & $\cdots \cdots$ & b2m \\
$\cdots \cdots$ & $\cdots \cdots$ & $\cdots \cdots$ & $\cdots \cdots$ & $\cdots \cdots$ \\
BM & bm1 & bm2 & $\cdots \cdots$ & bmm \\
\hline
\end{tabular}

Scaling of the relative importance of elements in a matrix.The scale of the relative importance of the elements in the matrix is shown in tabular form, as shown in Table 2.

Table 2. The table of relative importance of scale

\begin{tabular}{ll}
\hline Scale $(\mathrm{f}(\mathrm{x}, \mathrm{y}))$ & Definition \\
\hline 1 & $\mathrm{x}$ is as important as $\mathrm{y}$ \\
3 & $\mathrm{x}$ is slightly more important than $\mathrm{y}$ \\
5 & $\mathrm{x}$ is more important than $\mathrm{y}$ \\
7 & $\mathrm{x}$ is extraordinary more important than $\mathrm{y}$ \\
9 & $\mathrm{x}$ is absolutely more important than $\mathrm{y}$ \\
$2,4,6,8$ & Is the scale value corresponding to the \\
& intermediate state between the above two \\
& judgments
\end{tabular}


Evaluation matrix scoring method. (1) In the judgment matrix, if one element is considered to be equal in importance to another element, the quantized value is 1 ;

(2) In the judgment matrix, if one factor is considered to be slightly more significant than the other, the quantization value is 3 ; on the contrary, the quantization value is $1 / 3$;

(3) In the judgment matrix, if one element is considered to be more important than the other element, the quantization value is 5; on the contrary, the quantization value is $1 / 5$;

(4) In the judgment matrix, if one factor is considered to be more important than the other, the quantization value is 7 ; on the contrary, the quantization value is $1 / 7$;

(5) In the judgment matrix, if an element is considered to be extremely significant compared with another element, the quantization value is 9 ; on the contrary, the quantization value is $1 / 9$;

(6) If we consider the importance of one element to be more than the other, the quantized values should be taken as 2,4,6,8.

Expert scoring table example.Expert scoring can be based on the following tables, as shown in Table 3, Table 4.

Table 3. The table of primary factor weight

\begin{tabular}{|c|c|c|c|c|}
\hline Relative importance & \multirow{2}{*}{\multicolumn{4}{|c|}{ B1 B2 B3 B4 B5 B6 B7 B8 B9 B10 Wi }} \\
\hline Evaluation indicators B & & & & \\
\hline $\begin{array}{l}\text { Safety production emer } \\
\text { response assessment }\end{array}$ & emergency $\mathrm{B} 1$ & 1 & & \\
\hline Risk management & $\mathrm{B} 2$ & 1 & & \\
\hline emergency Plan & B3 & 1 & & \\
\hline Hazard monitoring and earlywa & ning B4 & 1 & & \\
\hline Response and recovery & B5 & & & \\
\hline Emergency team & B6 & & 1 & \\
\hline $\begin{array}{l}\text { Emergency equipment } \\
\text { materialsafety }\end{array}$ & and $\mathrm{B} 7$ & & 1 & \\
\hline Emergency training and drills & $\mathrm{B} 8$ & & 1 & \\
\hline Inspection and self-assessment & B9 & & & \\
\hline Others & B10 & & & 1 \\
\hline
\end{tabular}

Table 4. The table of organization system index weight

\begin{tabular}{|c|c|c|c|c|c|c|}
\hline Relative importance & Org & izational s & tem & (B1) & & \\
\hline Evaluation Indicators & & $\mathrm{C} 1 \quad \mathrm{C} 2$ & $\mathrm{C} 3$ & $\mathrm{C} 4$ & $\mathrm{C} 5$ & $\mathrm{Wi}$ \\
\hline Evaluation indicators & $\mathrm{C} 1$ & 1 & & & & \\
\hline Duty & $\mathrm{C} 2$ & 1 & & & & \\
\hline Management mechanism & $\mathrm{C} 3$ & & 1 & & & \\
\hline Related parties & $\mathrm{C} 4$ & & & 1 & & \\
\hline Laws and Regulations & C5 & & & & 1 & \\
\hline
\end{tabular}

Risk Management(B2) Indicator Weights, Contingency Plan(B3) Indicator Weights, Hazard Source Monitoring and Early Warning(B4) Indicator Weights, Responses and Recoveries(B5) Indicator Weights, B6 Indicator Weights, Emergency Equipment and Material Support(B7) Indicator weights, 
emergency training and drills(B8), check and self-assessment(B9) indicators such as the weight of the second-level elements in Table 4 and so on.

\section{Enterprise RiskRating Evaluation}

There are nine elements to set the surrounding environment and natural conditions, the scale of enterprises and relevant licenses, production technology, equipment and facilities, industry characteristics, occupational health, safety management, personnel, safety performance and compliance. Among them, the surrounding environment and natural conditions, the scale of enterprises and relevant licenses, production technology, equipment and facilities, industry characteristics and occupational health are collectively referred to as inherent risk factors; and safety management, personnel, safety performance and compliance are collectively referred to as safety management elements [8,9].

There are five elements of the industry characteristics that a total of five non-coal mining industry, hazardous chemicals industry, metallurgical non-ferrous metals industry, machining industry and other industries.

Level Standards. The enterprise's safety risk from low to high is divided into three levels, nine equal. Three levels are low risk, medium risk and high risk. Low risk level is divided into lower, low and medium risk, low and high risk. Medium risk level is divided into low and medium risk, medium risk, medium and high risk. High risk level is divided into high and low risk, high and medium risk, high risk.

Score Setting.The enterprise risk assignment of 1000 points, of which the inherent risk score of 700 points, safety management score of 300 points. The inherent risk and safety management of the various elements of scores are cumulative.

Enterprise risk score calculation formula $=700$ (inherent risk score of each factor) $+(300$ - score of each element of safety management). Table 5 shows the assignment of each factor.

Table 5. The table of the assignment of each element

\begin{tabular}{lll}
\hline Serial number & Elements & Score \\
\hline 1 & Surroundings and natural conditions & 60 \\
2 & Enterprise size and related licenses & 100 \\
3 & Production Process & 60 \\
4 & Equipment and facilities & 100 \\
5 & Industry characteristics of the elements & 300 \\
6 & occupational health & 60 \\
7 & Safety management & 120 \\
8 & personnel & 100 \\
9 & Safety performance and compliance with & 80 \\
& discipline & \\
\hline
\end{tabular}

Risk rating.According to the score of enterprise risk, it is divided according to the following rating standards as shown in Table 6. 
Table 6. The table of the division of enterprisesafety risk level division

\begin{tabular}{lll}
\hline Assessment level & Judging wait times & Review score standards \\
\hline \multirow{3}{*}{ Low risk level } & Low and low risk & 500 \\
& Low and medium risk & 550 \\
& Low and high risk & 650 \\
& Medium and low risk & 650 \\
Medium risk level & Medium and medium & 700 \\
& risk & 800 \\
& Medium and high risk & 800 \\
& High and low risk & 850 \\
High risk level & High and medium risk & 900 \\
& High and high risk & .
\end{tabular}

Risk Level Adjustment.The first-identified risk level can be adjusted according to the current production safety status of the enterprise, including risk level upgrade and downgrade.

(1) Risk level upgrade

If the manufacturer has a general production safety accident, or rectification of the hidden danger of the accident is not carried out on schedule, or fails to carry out the safety assessment on the major dangerous sources of the enterprise in that year, thesafety risk can be upgraded by one grade.

If there is a major production safety responsibility accident occurred in the manufacturing enterprise, or rectification of the hidden danger of the major accident is not carried out within the stipulated time, and if the production activity is not resumed after being examined and approved by the work safety supervision and administration department, the safety risk level will be raised two levels.

If a serious accident occurred in production safety accidents, the level ofsafety risk directly to a higher level.

(2) Risk level downgrade

After the initial determination of the risk level, the conditions for the production of the enterprise have improved considerably, or the risk rating can be reorganized if there is a need to downgrade after the rectification.

According to the level of production safety risk management level.The enterprise risks determined according to the inherent risk and safety management of the enterprise can be used for self-management of the enterprise as well as safety supervision and management departments at all levels to take corresponding safety supervision measures for the production safety of enterprises at all levels so as to rationally set the frequency of safety supervision and inspection[10].

Low-risk level of enterprise safety management mainly based on self-management, enterprises should be in accordance with relevant state laws and regulations, the enterprise rules and regulations, industry management requirements for self-restraint of the production and management. The safety supervision department can carry out no more than two supervisory inspections on the industry every year for low-risk enterprises and prioritize the handling of relevant certificates, commendations, post-holiday resumption of production and project approval.

Middle-level risk companies in the classification management activities account for a large proportion. Enterprises should actively promote the transformation in accordance with the requirements of the state, mainly in self-management of production safety management, supervision and inspection by the safety supervision department supplemented. The safety regulatory authorities carry out no more than four industry regulatory inspections on middle-risk enterprises each year.

High and low risk in high-risk level, high-risk enterprises in high-risk supervision and control of production safety is the focus of regulation. The municipal safety supervision department can carry 
out no less than twice a year, and the county safety supervision department carries out no less than four times of industrial supervisory inspection.

High-risk enterprises are the focus of safety supervision and rectification. For high-risk enterprises, the municipal safety regulatory authorities can carry out no less than six times a year. The county safety regulatory authorities can carry out supervisory inspections of the industry at least once every month and require high-risk enterprises to achieve high school risks within the specified time limit Level below the level.

\section{Conclusions}

According to the principle of "risk prioritization", it provides advice to regulators, gives priority to the supervision of the supervisory power and strengthens the supervision of enterprises with high risk levels.

(1) Focus on the risks, focus on the emphasis. From the enterprise's existing risks, safety management capabilities, safety benefits and personnel these four aspects of the company's outstanding problems of a comprehensive assessment.

(2) Qualitative and quantitative combination. The qualitative and quantitative analysis of the existing risks of enterprises should be taken, on the safety management capabilities, safety and efficiency and personnel evaluation of these four areas.

(3) Flexible classification, differential regulation. Based on the changes of the enterprise risk factors, the companies may adjust the risk level of the enterprise flexibly and assist the regulatory authorities in adopting corresponding measures for enterprises of different risk levels.

\section{Acknowledgements}

This work was supported by the Science Foundation of College of Engineering of Sichuan Normal University,Key Technology Projects for Prevention and Control of Serious Accidents in Production Safety of State Administration of Work Safety (sichuan-0003-2017AQ).

\section{References}

[1] XInxing Zhang. Enterprise Risk Management Problems and Countermeasures. Knowledge economy, Vol. 13(2017),p.74-76.

[2] Xuan Zhao. Enterprise Risk Management and Internal Control. Taxes, Vol.8 (2017) , p. 76.

[3] Bangqiong Yan. Talking about Enterprise Risk Management. Information Recording Material, Vol.7 (2017), p. 104-105.

[4] Wenxi Zheng, Lina Zhang,and so on.Security risk management and insurance knowledge. Beijing:China Labor and Socialsafety Publishing House, (2014) , p. 12-16.

[5] Shuqi Wu. Optimization of Enterprise Internal Control System Based on Total Risk Management. Foreign Trade and Economic Cooperation, Vol.5 (2017) , p. 138-139.

[6] Zhongyuan Sun. Research on Risk Level Classification Model of Production Enterprises Based on. Harbin University of Science and Technology, Vol.1 (2010) , p. 103-107.

[7] Xiaorui Dong. Application of Analytical Hierarchy Process. Digital world, Vol.6 (2017), p. 48-49.

[8] Chengping Han. Analysis of the elements of enterprise safety management. Economist, 2013(Vol.12) , p. 25-26.

[9] Sun Bin. Research on Enterprisesafety Risk Management. Chinese coal, Vol.10 (2006), p. $70-71$. 
[10]Quan Zhang, Chen Quan, an so on. Evaluation of the Importance of the Hazard Source and Its Graded Monitoring and Management[J]. Journal of Tianjin Polytechnic University, Vol.2 (2012), p. 67-72. 